\title{
Walking and running on treadmill: the standard criteria for kinematics studies
}

\author{
Johnny Padulo1,2 \\ Karim Chamari2,3 \\ Luca Paolo Ardigò 4
}

1 Sport Science, University e-Campus, Novedrate, Italy

2 Tunisian Research Laboratory 'Sports Performance Optimization', National Center of Medicine and Science in Sport, Tunis, Tunisia

3 Research and Education Centre Aspetar, Qatar Orthopaedic and Sports Medicine Hospital, Doha, Qatar

${ }^{4}$ School of Exercise and Sport Science, Department of Neurological and Movement Science, University of Verona, Italy

\section{Corresponding author:}

Luca Paolo Ardigò

School of Exercise and Sport Science, Department of Neurological and Movement Science, University of Verona

via Felice Casorati, 43

37131 Verona, Italy

E-mail: luca.ardigo@univr.it

\section{Summary}

In humans, walking and running represent the most studied locomotion forms. The motorized treadmill has always been a very useful scientific tool, because it allows administer a variety of speed/slope combinations, which is not always easy-to-find in nature. The purpose of this short communication is to help improve the scientific use of the treadmill and explain some simple kinematics variables together with simple ways to measure/calculate them.

KEYWORDS: biomechanics, evaluation, gait analysis, physical activity measurement, sports rehabilitation programs.

\section{Introduction}

Over the past decade there has been an increasing interest about the use of the motorized treadmill for studies about walking and running. However, any scientific study can lead to a valuable scientific progress only if the resulting study report results to be easily understood by others. Compliance to standard rules such as definitions, reliability (precision and accura$c y)$, and accuracy of measurement is required ${ }^{1}$. To the authors' opinion, to improve the quality of the research, the correct treadmill use should be described in three common contexts:

1. Measurement reliability

2. Video Analysis

3. Kinematics.

\section{Measurement reliability}

For the use of a treadmill, in addition to the guidelines of its manufacturer, there are several suggestions about its' calibration (i.e., speed and slope check) for a good experimental set-up. Moreover, the calibration phase is necessary to guarantee the reproducibility of the measures $^{1}$. Some authors ${ }^{2-4}$ have shown a simple, very accurate and easy calibration method by using an odometer (Trumeter, Radcliffe, UK). The total distance covered was recorded by the odometer attached to the treadmill. The accuracy of the odometer is verified by comparing the results obtained by the odometer with those obtained by multiplying the actual number of complete treadmill belt revolutions in 6 minutes by the length of the belt.

The easiest way to calibrate the speed of a treadmill is to measure the length of the belt and count the number of belt revolutions over a certain amount of time. To calibrate the treadmill speed ${ }^{5}$, these steps has to be followed:

1. Measure the length of the belt in meters.

a. Place a meter stick on the belt surface and mark a starting point.

b. Advance the belt by hand, marking the belt $1 \mathrm{~m}$ at a time until you return to the starting point. Note the resulting value as the belt length. The belt length measurement has to be done on a side (right or left) of the belt, near its edge. Indeed, "central" measurements could allow nonvertical measures and thus biasing the resulting length. For instance, any lateral deviation of the meter stick (even of few millimeters) will automatically result in a measure error.

2. Draw a small piece of tape - as a reference - on the treadmill belt and a corresponding piece of tape on the treadmill.

3. Turn on the treadmill and accelerate it to a given speed by using the speed control.

4. Count 20 revolutions of the tape on the belt while tracking the time with a stopwatch. Start your watch as the tape first moves past a taped point beside the belt, beginning the count with 0 . 
5. Convert the number of revolution to revolutions per minute (rev $\left.\cdot \mathrm{min}^{-1}\right)$. For example, if the belt made 20 complete revolutions in $35 \mathrm{sec}$, then 35 $\mathrm{sec} / 60 \mathrm{sec} \cdot \mathrm{min}^{-1}=0.58 \mathrm{~min}, 20 \mathrm{rev} / 0.58 \mathrm{~min}=$ $34.3 \mathrm{rev} \cdot \mathrm{min}^{-1}$.

6. Multiply the calculated revolutions per minute (Step 5) by the belt length (Step 1). This gives the belt speed in meters per minute $\left(\mathrm{m} \cdot \mathrm{min}^{-1}\right)$. For example, if the belt length is $5.03 \mathrm{~m}$, then $34.3 \mathrm{rev}$. $\mathrm{min}^{-1} \cdot 5.03 \mathrm{~m} \cdot \mathrm{rev}^{-1}=172.53 \mathrm{~m} \cdot \mathrm{min}^{-1}$.

7. To convert meters per minute to miles per hour, divide the result of Step 6 by $26.8\left(\mathrm{~m} \cdot \mathrm{min}^{-1}\right) \cdot(\mathrm{mi}$ $\left.\cdot \mathrm{hr}^{-1}\right)^{-1}: 172.53 \mathrm{~m} \cdot \mathrm{min}^{-1} /\left[26.8\left(\mathrm{~m} \cdot \mathrm{min}^{-1}\right) \cdot(\mathrm{mi}\right.$. $\left.\left.\mathrm{hr}^{-1}\right)^{-1}\right]=6.44 \mathrm{mi} \cdot \mathrm{hr}^{-1}$; to convert meters per minute to kilometer per hour, divide the result of Step 6 by $16.7\left(\mathrm{~m} \cdot \mathrm{min}^{-1}\right) \cdot\left(\mathrm{km} \cdot \mathrm{h}^{-1}\right): 172.53 \mathrm{~m}$. $\min ^{-1} / 16.7=10.33 \mathrm{~km} \cdot \mathrm{h}^{-1}$.

The slope calibration requires a very simple method, which, even if rudimentary, is yet very effective:

1. Use a carpenter's level to ensure that the treadmill is leveled-off, and check the zero output on the grade meter under this condition (with the treadmill electronics turned on). If the grade meter does not read zero, follow these steps to make the adjustment (usually by using a small screw on the face of the treadmill controller dial).

2. Elevate the treadmill so that the percentage grade dial reads approximately $20 \%$. Measure the exact rise and run of the bubble inside the tube of the level.

3. Calculate the grade from the rise over the run and adjust the treadmill meter to read that exact grade. For example, if the rise is 4.5 in $(11.4 \mathrm{~cm})$ and the run is 22.5 in $(57.2 \mathrm{~cm})$, the fractional grade is calculated as follows:

Grade $=$ rise $/$ run $=4.5 \mathrm{in} / 22.5$ in $=0.20$ or $20 \%$.

\section{Video analysis}

The video analysis (VA) represents the most reliable and easy method for studying the human movement. VA based on motion capture with passive or active markers is useful for reconstructing along the trigonometric axes the movement in the space ( $x$ and $y$ over a two-dimensional [2D] plane and $x-y-z$ within a three-dimensional $[3 D]$ volume). Such a reconstruction can also be performed over time on a single-axis basis. $2 D$ analysis represents the most used method, because its experimental set-up requires relatively low cost tools. Moreover and recently, different manufactures of camcorders placed on the market different models ${ }^{6}$ capable of high-speed recordings $(60 \div 1000 \mathrm{fps}$ [frames per second] or $\mathrm{Hz})$ and different resolutions (i.e., FH20: 480 [rows] · 360 [columns] at $210 \mathrm{fps}, 224 \cdot 168$ at $420 \mathrm{fps}, 224 \cdot 56$ at $1,000 \mathrm{fps})$. To calculate the error $(\mathrm{E})$ of the $2 D$ spatial resolution is very easy with the following equation:

E e.g., y (vertical) $(\mathrm{mm})=210(\mathrm{fps}) /[(\mathrm{D} \times 1000) / \mathrm{R}(480)]$; where $D$ (meters) is the vertical length of the sagittal plane studied and $\mathrm{R}$ the resolution of the camera (a 480 [rows] at 210 [fps] one, as an example here in the equation). Moreover, a proper sample frequency (fps or $\mathrm{Hz}$ ) is necessary, especially to assess CT (contact time) or FT (flight time) during running when the speed is high. In fact, at speed $>14 \mathrm{~km} \cdot \mathrm{h}^{-1}$, the average SF (Stride Frequency) is $3.5 \mathrm{~Hz}$ and to study the time (ms) of CT and FT is desirable to use a highspeed instrumentation. As an alternative you may detect by eye and count the steps per one minute and, by knowing the treadmill speed, calculate SF and SL (stride length) 7,8 .

The $30 \mathrm{fps}$ traditional camera sample rate is effective for low speed $\left(\leq 9 \mathrm{~km} \cdot \mathrm{h}^{-1}\right)$, while for $9 \div 14.4 \mathrm{~km} \cdot \mathrm{h}^{-1}$ a $50 \mathrm{fps}$ is required $\mathrm{d}^{9,10}$. The $100 \mathrm{fps}$ sampling showed a good reliability at $14.4 \div 20 \mathrm{~km} \cdot \mathrm{h}^{-1} 11$, and for speeds exceeding $20 \mathrm{~km} \cdot \mathrm{h}^{-1}$ is recommended a device with $\geq 250 \mathrm{fps}$ sampling rate ${ }^{12,13}$. In every case, the optimal sample rate should be calculated following the Nyquist-Shannon sampling theorem ${ }^{14}$. In particular, the theorem states that, under suitable assumptions, in an analog-to-digital conversion the minimum sampling frequency necessary to avoid ambiguity and loss of information (e.g., aliasing) in the reconstruction of the original analog signal is equal to twice its maximum frequency. The theorem, which appeared for the first time in 1949 in an article by C. E. Shannon ${ }^{14}$, should be ascribed to WhittakerNyquist-Kotelnikov-Shannon, according to the chronological order of those scientists who proposed increasingly generalized versions of the theorem. Sampling is the first step of the process of analog-todigital conversion of a signal. It means taking a certain number of samples every second from a continuous analog signal. $\Delta t$ is the sampling interval, while $f_{x}$ $=1 / \Delta t$ is the sampling frequency. The result is an analog signal over discrete time.

Once chosen a certain sampling, particular attention should be used for the positioning of the camera, which is normally located on a $1.5 \mathrm{~m}$-height tripod, $4 \mathrm{~m}$ from and perpendicular to the acquisition space, in order to be perpendicular to the subjects' sagittal plane ${ }^{15}$. There should always be verification about the proper placement of the objective of the camera with respect of the field of view of interest. The more you get closer to the object to be recorded and the smaller the field of acquisition is, but the more accurate (low error) ${ }^{15}$ is the resulting movie as well. Then the recorded movie will be studied with some motion analysis software.

\section{Kinematics}

A habituation of the subject with the locomotion on the treadmill is needed to allow the reliability of a proper measurement on it. Usually, the subjects' previous treadmill experience is not taken into consideration and they are asked to complete an adequate habituation session on it (see for a simple experimental set-up as well). 
Moreover, a lot of attention has to be paid to the shoes $^{16}$ for the reliability of the measures ${ }^{17}$. This is especially true for shoes which are worn in longitudinal studies ${ }^{18}$. Besides, it is possible to calculate the mechanical energy absorbed by the shoe. In fact the shoe's kinetic energy (KEY) at its initial impact on the ground may be calculated with this equation: $\mathrm{KEY}=$ $1 / 2 \cdot m \cdot v^{2}$ (where $m$ is the shoe's mass and $v$ its speed at the impact) ${ }^{16}$. Usually, the mass of the shoes is highly variable $(0.1 \div 0.5 \mathrm{~kg})$ and depends on the runner's body weight and his/her usual speed $^{18-20}$.

A simple kinematics study is represented by the footstep analysis in terms of CT, FT, step frequency (SF $[\mathrm{Hz}])$, and step length (SL $[\mathrm{m}])$ detection. These data may be analyzed after video recording according to the method of Mero and Komi21. In some cases, footstep data (CT, FT, SF, SL; with a precision of $1 \mathrm{~ms}$ ) are measured by using photocells-based timing system. A 2-m length of this system may be secured along a treadmill belt 22 . With this photogrammetric system CT and FT may be calculated for both the left and right foot together. Running $\mathrm{CT}$ is defined and calculated as the time between the initial foot/shoe contact/frame with the ground and the last foot/shoe contact/frame before the take-off. FT is defined and calculated as the time between the take-off and the next initial contact of the contra-lateral foot. Initial contact and take-off may be visually detected. Stride frequency is calculated as $S F=1 /(C T+F T)$. $S L$ is calculated with the following equation: $S L=$ speed $[\mathrm{m}$. $\mathrm{S}^{-1} \mathrm{~J} / \mathrm{SF}$. Some authors indentified in the stride cycle: Foot Strike (FS as to corresponding to the first photogram in which the foot in contact with the ground); Toe Off (TO as to corresponding to the first photogram in which the foot is no more in contact with the ground ${ }^{23,24}$. As an example of a specific matter investigated by using the simple kinematics analysis just described, Ardigò et al. ${ }^{25}$ and Hasegawa et al. ${ }^{24}$ classified subjects' FS by three different patterns: rear-foot strike (RFS), mid-foot strike (MFS) and forefoot strike (FFS). RFS was defined as a foot strike in which the point of the first contact of the foot with the ground was the heel, the rear third part of the sole and in which the mid-foot or forefoot portion did not have any contact at foot strike ${ }^{24}$. MFS was defined as a foot strike in which the point of the first contact of the foot with the ground were the rear third of the sole and the mid-foot together, i.e., the whole sole ${ }^{24}$. FFS was defined as a foot strike in which the point of the first contact of the foot with the ground was the forefoot, the front half of the sole, and in which the heel did not have any contact at the foot strike (see for a simple experimental set-up as well) ${ }^{24}$.

As another example of simple kinematics application, by knowing the timing of the step it is possible to calculate the mechanical internal kinematic work (WINT) with a simple equation by Nardello et al.: ${ }^{26} \mathrm{~W}_{\text {INT }}=\mathrm{SF}$ $\cdot v \cdot\left(1+\left(\mathrm{DF} \cdot(1-\mathrm{DF})^{-1}\right)^{2}\right) \cdot q$. Here DF is the duty factor, i.e., the average $\%$ of the total cycle duration, at which a foot is in contact with the ground. $q$ is a compound dimensionless term with constant value of
0.08 (in level, 0.10 in slope) referring to the inertial properties of the limbs and the mass partitioned between the limbs and the rest of the body. Other biomechanical more complex variables featuring running can be estimated by using the simple kinematics variables just described. For example, Morin et al. ${ }^{27}$ proposed a method for measuring the leg and the vertical stiffness from CT (expressed in s), FT (expressed in $\mathrm{S}), v$, leg length (I, expressed in $\mathrm{m}$ ) and body mass. In particular, the vertical stiffness is calculated as:

$\mathrm{K}_{\mathrm{VERT}}=\mathrm{m} \cdot \mathrm{g} \cdot \frac{\pi}{2} \cdot\left(\frac{\mathrm{FT}}{\mathrm{CT}}+1\right) \cdot\left(\frac{\mathrm{m} \cdot \mathrm{g} \cdot \frac{\pi}{2} \cdot\left(\frac{\mathrm{FT}}{\mathrm{CT}}+1\right)}{\mathrm{m}} \cdot \frac{\mathrm{CT}^{2}}{\pi^{2}}+\mathrm{g} \cdot \frac{\mathrm{CT}^{2}}{8}\right)^{-1}$,

and the leg stiffness is calculated as:

$\mathrm{K}_{\mathrm{LEG}}=\mathrm{m} \cdot \mathrm{g} \cdot \frac{\pi}{2} \cdot\left(\frac{\mathrm{FT}}{\mathrm{CT}}+1\right) \cdot\left(\mathrm{l}-\sqrt{1^{2}-\left(\frac{\mathrm{v} \cdot \mathrm{CT}}{2}\right)^{2}}+\left(\frac{\mathrm{m} \cdot \mathrm{g} \cdot \frac{\pi}{2} \cdot\left(\frac{\mathrm{FT}}{\mathrm{CT}}+1\right)}{\mathrm{m}}\right) \cdot \frac{\mathrm{CT}^{2}}{\pi^{2}}+\mathrm{g} \cdot \frac{\mathrm{CT}^{2}}{8}\right)^{-1}$,

where $\mathrm{g}$ is the gravity acceleration constant (in $\mathrm{m} \cdot \mathrm{s}^{-2}$ ).

\section{For a simple experimental set-up}

- The first step is about the reliability of the kinematics analysis on treadmill vs field (track and field). Jones and Doust solved this issue ${ }^{28}$. In particular, a $1 \%$ treadmill slope replies most accurately an outdoor track and field setting on the measurement/calculation of the metabolic cost (Cr, i.e., the metabolic expenditure over resting per unit distance travelled $\left.\left[\mathrm{J} \cdot \mathrm{kg}^{-1} \cdot \mathrm{m}^{-1}\right]\right)$ at different speeds $\left(10.51<18.00 \mathrm{~km} \cdot \mathrm{h}^{-1}\right)$.

- The second step is about the selection of some meaningful speed value. In this regard Padulo et al. (2012) proposed a simple Iso-Efficiency Speed over slope (IES, $\mathrm{km} \cdot \mathrm{h}^{-1}$ ) equation for trained runners ${ }^{20}$. IES for each participant at a $0 \%$ slope (IESo) was calculated as the average speed featuring the participant's best performance in a $10,000 \mathrm{~m}$ race (recorded within the 6 month period prior to testing), minus $1 \mathrm{~km} \cdot \mathrm{h}^{-1}$. Research suggested this corresponds to $\sim 50 \%$ maximal oxygen consumption ${ }^{29}$ and requires a metabolic cost $\left(\mathrm{Cr}_{0}\right)$ of $4.0 \mathrm{~J} \cdot \mathrm{kg}^{-1} \cdot \mathrm{m}^{-1} .30$ Slope IES results from the following equation:

$$
\text { IES }=\frac{\text { IES }_{0} \cdot\left(0.20 \cdot \text { slope } \%+\mathrm{Cr}_{0}\right)}{\mathrm{Cr}_{0}}
$$

- The third step is about the habituation. The subjects should practice on the treadmill for at least 10 $\mathrm{min}^{31}$, which represent the good time for treadmill familiarization for subjects up to $65 \mathrm{yrs}$, while at least $15 \mathrm{~min}$ are necessary for ages over $65 \mathrm{yrs}^{32}$.

- The fourth step concerns the time needed in case of a metabolic cost investigation together with a kinematics one. For each speed the minimum time must not be less than $5 \mathrm{~min}$, because it takes $4 \mathrm{~min}$ to the metabolic cost to attain a physiologi-

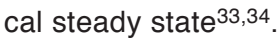


- The fifth step concerns the minimum step number required for high quality research. It is 64 steps $^{35}$ for subject $18-20,36,37$ with a lot of experience and 400 steps for beginners ${ }^{38}$. Such step number choices are considered adequate to cope adequately with actual footstep variability ${ }^{35,38}$.

The present article synthesizes the current knowledge about the use of the treadmill as a device for studies about gait kinematics. Therefore it can be of interest for sport scientists and coaches, who aim to perform effectively simple tests to assess athletes' gait kinematics variables. This review conforms to required ethical standards ${ }^{39}$.

\section{References}

1. Winter EM, Fowler N. Exercise defined and quantified according to the Systeme International d'Unites. J Sports Sci. 2009;27(5):447-460.

2. Di Michele R, Di Renzo AM, Ammazzalorso S, Merni F. Comparison of physiological responses to an incremental running test on treadmill, natural grass, and synthetic turf in young soccer players. J Strength Cond Res. 2009;23(3):939-945.

3. Grant S, McMillan K, Newell J, et al. Reproducibility of the blood lactate threshold, 4 mmol.I(-1) marker, heart rate and ratings of perceived exertion during incremental treadmill exercise in humans. Eur J Appl Physiol. 2002;87(2):159-166.

4. McMillan K, Helgerud J, Grant SJ, et al. Lactate threshold responses to a season of professional British youth soccer. Br J Sports Med. 2005;39(7):432-436.

5. Howley ET. The exercise testing laboratory. Resource manual for guidelines for exercise testing and prescription, Philadelphia, PA: Lea \& Fegiber. 1988;409.

6. Balsalobre-Fernandez C, Tejero-Gonzalez CM, Campo-Vecino JD, Bavaresco N. The concurrent validity and reliability of a low-cost, high-speed camera-based method for measuring the flight time of vertical jumps. J Strength Cond Res. 2013. [Epub ahead of print]

7. Rowlands AV, Stone MR, Eston RG. Influence of speed and step frequency during walking and running on motion sensor output. Med Sci Sports Exerc. 2007;39(4):716-727.

8. Padulo J, Powell D, Milia R, Ardigo LP. A paradigm of uphill running. PLoS One, 2013;8(7):e69006.

9. Diss CE. The reliability of kinetic and kinematic variables used to analyse normal running gait. Gait Posture. 2001;14(2):98103.

10. Hausswirth C, Bigard AX, Guezennec CY. Relationships between running mechanics and energy cost of running at the end of a triathlon and a marathon. Int J Sports Med. 1997;18 (5):330-339.

11. Cavanagh PR, Pollock ML, Landa J. A biomechanical comparison of elite and good distance runners. Ann N Y Acad Sci. 1977;301:328-345.

12. Jordan K, Challis JH, Newell KM. Speed influences on the scaling behavior of gait cycle fluctuations during treadmill running. Hum Mov Sci. 2007;26(1):87-102.

13. McKenna M, Riches PE. A comparison of sprinting kinematics on two types of treadmill and over-ground. Scand J Med Sci Sports. 2007;17(6):649-655.

14. Shannon CE. Communication Theory of Secrecy Systems. Bell Syst Tech J. 1949;28(4):656-715.

15. Belli A, Rey S, Bonnefoy R, Lacour JR. A Simple Device for Kinematic Measurements of Human Movement. Ergonomics. 1992;35(2):177-186.

16. McNair PJ, Marshall RN. Kinematic and kinetic parameters as- sociated with running in different shoes. $\mathrm{Br} \mathrm{J}$ Sports Med. 1994;28(4):256-260.

17. Donner A, Eliasziw M. Sample size requirements for reliability studies. Stat Med. 1987;6(4):441-448.

18. Padulo J, Degortes N, Migliaccio GM, et al. Footstep manipulation during uphill running. Int J Sports Med. 2013;34(3):244-247.

19. Padulo J, Annino G, Migliaccio GM, D'Ottavio S, Tihanyi J. Kinematics of running at different slopes and speeds. J Strength Cond Res. 2012;26(5):1331-1339.

20. Padulo J, Annino G, Smith L, et al. Uphill running at iso-efficiency speed. Int J Sports Med. 2012;33(10):819-823.

21. Mero A, Komi PV. Effects of supramaximal velocity on biomechanical variables in sprinting. J Appl Biomech. 1985;1(3):240252.

22. Oliver JL, Stembridge M. Use of a heart rate to ground contact time index to monitor and predict middle-distance running. Eur J Sport Sci. 2011;11(6):431-436.

23. Ciacci S, Di Michele R., Merni F. Kinematic analysis of the braking and propulsion phases during the support time in sprint running. Gait Posture. 2010;31(2):209-212.

24. Hasegawa $\mathrm{H}$, Yamauchi T, Kraemer WJ. Foot strike patterns of runners at the $15-\mathrm{km}$ point during an elite-level half marathon. J Strength Cond Res. 2007;21(3):888-893.

25. Ardigò LP, Lafortuna C, Minetti AE, Mognoni P, Saibene F. Metabolic and mechanical aspects of foot landing type, forefoot and rearfoot strike, in human running. Acta Physiol Scand. 1995;155(1):17-22.

26. Nardello F, Ardigò LP, Minetti AE. Measured and predicted mechanical internal work in human locomotion. Hum Mov Sci. 2011;30(1):90-104.

27. Morin JB, Dalleau G, Kyrolainen H, Jeannin T, Belli A. A simple method for measuring stiffness during running. J Appl Biomech. 2005;21(2):167-180.

28. Jones AM, Doust JH. A $1 \%$ treadmill grade most accurately reflects the energetic cost of outdoor running. J Sports Sci. 1996;14(4):321-327.

29. Menier DR, Pugh LG. The relation of oxygen intake and velocity of walking and running, in competition walkers. J Physiol. 1968;197(3):717-721.

30. Di Prampero PE, Capelli C, Pagliaro P, et al. Energetics of best performances in middle-distance running. J Appl Physiol. 1993;74(5):2318-2324.

31. Van de PM, Hagemeister N, St-Onge N, Parent G, de Guise JA. Habituation to treadmill walking. Biomed Mater Eng. 2006;16(1):43-52.

32. Wass E, Taylor NF, Matsas A. Familiarisation to treadmill walking in unimpaired older people. Gait Posture. 2005;21(1): 72-79.

33. Chamari K, Moussa-Chamari I, Boussaidi L, Hachana Y, Kaouech F, Wisloff U. Appropriate interpretation of aerobic capacity: allometric scaling in adult and young soccer players. $\mathrm{Br}$ J Sports Med. 2005;39(2):97-101.

34. Morgan DW, Martin PE, Krahenbuhl GS. Factors affecting running economy. Sports Med. 1989;7(5):310-330.

35. Belli A, Lacour JR, Komi PV, Candau R, Denis C. Mechanical step variability during treadmill running. Eur J Appl Physiol Occup Physiol. 1995;70(6):510-517.

36. Padulo J, Annino G, Tihanyi J, et al. Uphill Race Walking At IsoEfficiency Speed. J Strength Cond Res. 2013;27(7):1964-1973.

37. Padulo J, Annino G, D'Ottavio S, et al. Footstep analysis at different slopes and speeds in elite race walking. J Strength Cond Res. 2013;27(1):125-129.

38. Owings TM, Grabiner MD. Measuring step kinematic variability on an instrumented treadmill: how many steps are enough? J Biomech. 2003;36(8):1215-1218.

39. Padulo J, Oliva F, Frizziero A, Maffulli N. Muscles, Ligaments and Tendons Journal. Basic principles and recommendations in clinical and field science research. MLTJ. 2013;4:250-252. 